\title{
Чумаков В.A. \\ К анализу конституций советского и постсоветского периодов российской государственности
}

\author{
Философский клуб при ННГАСУ
}

(Россия, Нижний Новгород)

doi:10.18411/spc-20-01-2018-09

idsp: 000001:spc-20-01-2018-09

\section{Аннотация}

В докладе установлено, что источником правовой системы является политическая воля господствующего класса,доказывающая научность регулятивно диалектической концепции социальной философии. Выявлено абстрактное определение общественного устройства РФ, названное неопределённым термином «конституционный строй». Проведён анализ некоторых статей Конституции РФ и их сравнение с однородными статьями Конституции Советского Союза. Показано, что статьи Конституции РФ реально определяют «конституционный строй» как буржуазное, капиталистическое общество.Определены цели существования и развития рассматриваемых государств.

Ключевые слова: правовая система, цель общества, статьи Конституции, регулятивно-диалектический механизм.

\section{Abstract}

The report established that the source of the legal system is the political will of the ruling class, proving the scientific regulatory and the dialectical concept of social philosophy. Identified an abstract definition of the social structure of the Russian Federation, called undefined term "constitutional order".The analysis of some articles of the Constitution of the Russian Federation and comparing them with similar articles of the Constitution of the Soviet Union. It is shown that articles of the Constitution actually define the "constitutional order" as a bourgeois, capitalist society. Define the objectives of the existence and development of the countries.

Keywords: legal system, the purpose of the society, articles of the Constitution, regulatory and dialectical mechanism.

Юридические науки призваны изучать, развивать и разъяснять различные отрасли правовой системы государства. В советском периоде юриспруденция различаласуществующие правовые акты - «источники права в юридическом смысле» от «источников права в материальном смысле» - тех политических сил, ответственных за формирование юридического права. Современные авторы учебников правоведения предпочитают не упоминать об этой зависимости юридических текстов от политическогодиктата правящего класса. Только в одном учебнике была найдена ссылка на этот вид источника права, сопровождаемая любопытной пометкой: «Никакого полезного прикладного значения для понимания конституционного права она не имеет» [1, с. 18], по-видимому, рассчитанной на незыблемость буржуазной власти, и невозможность появления новых «источников права в материальном смысле», способных заменить буржуазное право, отрицая при этом закономерности регулятивно - диалектическогомеханизма развития социума [4, с. 5-11].

Основная мысль регулятивно - диалектического механизма социального развития заключается в том, что окружающиймир, бытие информирует о своём состоянии разумный комплекс человека, который определяет действия по приведению бытия в новое, желаемое человеку состояние, запуская в действие регулятивный контур субъект - объектного управления. 
В качестве субъекта управления выступают как отдельные лица, так и коллективное волеизъявление - общественное сознание. В объект управления входят как материальные предметы, так и отдельные лица и коллективные образования. Во взаимодействие субъектов и объектов управления социальной материи, вариативного регулятивно - диалектического механизма большую роль играет политическая субординация участников социальных отношений,появляющаяся уже на стадии сословной дифференциации первобытного общества, на стадии появления социального господства и подчинения, появления эксплуататоров и эксплуатируемых.

Управление подчинением эксплуатируемых масс происходило сначала на основании устно сформулированных властными лицами законов существования общины, племени, а затем и письменно зафиксированных уложений, первых правовых систем. Вспомним хотя бы «Русскую правду» Ярослава Мудрого, устанавливающую жёсткое сословное разделение людей. Власти диктовали свою политическую волю по управлению подданными, подчинёнными массами. Это доказывает, что основой для разработки источников правовой системы служит политическая воля, господствующая, на данный момент, в государстве. С изменением социально экономического и политического устройства появляется необходимость отражения новых условий развития общества в нормативно - правовой практике.

В прошлом веке произошли две смены общественного устройства России. Это октябрь 1917 года, когда власть взяла партия большевиков, представляющая интересы трудящихся масс, и контрреволюционное сползание властных структур СССР в капиталистическое болото действительности РФ, произошедшее в 1991 - 1993 году.

К сожалению, в конце восьмидесятых годов прошлого века партийные и государственные власти Советского Союза не смогли обеспечить нормальное снабжение населения продовольственными продуктами и товарами широкого потребления, чем воспользовались переродившиеся мелкобуржуазные силы на верхних этажах власти, совершившие контрреволюционный переворот. Фактически случилось повторение в замедленном темпе событий, приведших к февральской революции 1917 года. Произошло разгосударствление средств производства, появление частной собственности и установление капиталистических отношений. Для придания законности новым условиям жизни в 1993 году народу был навязан новый «источник права в материальном смысле» - ельцинскому окружению удалось через референдум протащить либерально - демократическую, а по смыслу буржуазную Конституцию.

Желание легитимации капитализма буржуазной властью выразилось в постоянномочернениисоветского периода жизни России. Делается многое, чтобы народ, молодое поколение забыло о существовании советской власти или имело о ней превратное представление. Некоторые авторы юридических учебников, описывая советский период, негативно подчёркивали его тоталитарный характер, следуя в этом западным социологам, которые с точки зрения буржуазных свобод исследовали советский период развития России. Пора российскому народу понять, что без общей цели, без единства партии и народа, которую поначалу и правда довольно жестоко проводила власть большевиков, нельзя было построить социалистическую Россию. Малограмотную страну необходимо было, по словам В.И. Ленина, не только завоевать, но и убедить в реальности цели большевиков - построения бесклассового общества с общенародной собственностью на средства производства, отсутствием эксплуатации человека человеком и обширными правами народа.

Советская Конституция в первом разделе «Основы общественного строя и политики СССР» определяла политическую и экономическую систему, а также внешнюю политику государства, откровенно указывая на создание социалистического общества, свободного от эксплуатации человека человеком. В статье 15 Конституции СССР определялась цель развития страны: «...наиболее полное удовлетворение 
растущих материальных $u$ духовных потребностей людей». Юристам, разрабатывавшим Конституцию победившей контрреволюции, пришлось долго ломать голову над названием первой главы, которая определяла характер общества. Указать в ней восстановление капиталистических, буржуазных порядков они не посмели, опасаясь, что народ на референдуме проголосует против неё. Было предложено назвать будущее общество «конституционным строем», а первую главу так и озаглавить: «Основы конституционного строя». Этим конституция фактически освобождалась от необходимости однозначного определения будущих социально-экономических отношений, которые и так недвусмысленно задавались содержанием её статей, как буржуазных. Вообще создавалась довольно неказистая словесная конструкция конституция страны с конституционным строем, что в лингвистическом отношении выглядит довольно неуклюже и нелепо. Масло - масляное. В общем, сапоги всмятку, как выражался А.П.Чехов.

Статья 3 Конституции РФ утверждает, что народ страны является единственным источником власти и её непосредственное выражение происходит через референдумы и свободные выборы. На практике неоднократные попытки КПРФ организовать народное волеизъявление не были разрешены буржуазными властями РФ. В законе «О референдуме» 2007 г. произошло дальнейшее ужесточение условий организации референдумов, фактически отменившие их проведение. «Свободные» выборы проводятся при большом давлении властных органов в пользу «Единой России» и её кандидатов, а также с большими нарушениями в их проведении и подсчёте голосов. Во многих городах под давлением областной администрации общенародные выборы градоначальника стали подменять его выбором депутатами городской думы, что ещё больше уменьшило объём народного волеизъявления.

Происходит постепенный отход государства от демократического устройства $c$ республиканской формой правления, которая записана в первой статье Конституции РФ. В пункте 4 данной статьи запрещцено присвоение власти, а также её захват или присвоение властных полномочий. Однако своё становление существующая власть начала с силового присвоения властных полномочий, произошедшее в 1993г. после расстрела танками Верховного Совета РСФСР, произведённого по распоряжению Ельцина, открыто продемонстрировав двойные стандарты. Самим можно, другим нельзя. Последующий рост авторитаризма, был лишь несколько приукрашен представительной властью и якобы независимой судебной системой.

В статье 7 говорится, что РФ является социальным государством, которое подразумевает всеобщее благосостояние и всеобщее благоденствие, основанное на перераспределении материальных благ, в соответствие с принципом социальной справедливости. К сожалению, внутренняя политика государства и буржуазной партии власти противоречит этому положению. Вместо выравнивания материального положения граждан, в стране проводится курс на увеличения богатства олигархов и дальнейшее разорение бедноты. Растёт число миллиардеров.

Страна разделена на два противоположных лагеря. О величине децимального коэффициента, характеризующего расслоение общества, власти предпочитают умалчивать, хотя он во много раз превышает его максимальное значение, предваряющее социальный взрыв. При этом существует проверенный во многих развитых капиталистических странах способ получения необходимых финансовых средств для проведения социальной политики - прогрессивное налогообложение. Богатые должны делиться своими доходами с беднейшими слоями населения. В РФ это положение предано забвению, согласно официальному мнению президента, а распределение доходов поставлено с ног на голову - богачи в процентном отношении платят даже меньше налогов, чем их менее удачливые бедные сограждане. 
Статьи 8, 9, 35, 36, 37 утверждают основные элементы буржуазного конституционного строя: частную собственность, в том числе и на землю, а также право на свободный труд, ведущий к унижающей человека безработице.

Статья 9 содержит взаимно исключающие пункты. В части 1 утверждается, что: «Земля и другие природные ресурсы используются и охраняются...как основа жизни и деятельности народов, проживающих на соответствующей территории». А в пункте 2 говорится, что: «Земля и другие природные ресурсы могут находиться в частной...и иных формах собственности». Наши земли с природными ресурсами находятся, в большинстве своём, в частной собственности, не связанной с «проживающим» на ней народом. Однако своей прибылью частный собственник забывает делиться с этим народом.

Конституция РФ предписывает разделение и самостоятельность законодательной, исполнительной и судебной властей (статья 10). В действительности существуют однозначные связи законодательной и судебной власти с исполнительной. Это можно проследить как по практике принятия законопроектов в Государственной Думе, так и по некоторым судебным решениям. Член Конституционного Суда В.Г. Ярославцев в 2009 году заявил испанской газете «Раis», что под руководством первых лиц государства судебная власть в России стала инструментом власти исполнительной.

Статьёй 13 утверждается идеологическое многообразие, многопартийность и равенство партий перед законом. На деле предпочтение в стране отдано партии власти - «Единой России», а её идеология антисоветизма, обогащения и бездумного потребительства, негласно принята в качестве государственной политики, молчаливо поддерживаемая церковью. В пункте 5 лицемерно вводится запрет «...на насильственное изменение основ конституционного строя...», того, что совериили сами вдохновители буржуазной конституции в 1993 году. По содержанию он повторяет 4 пункт статьи 3.

В статье 14 обозначена светскость российского государства, что никакая религия не может быть государственной. В том, что этот пункт конституции не исполняется можно судить по эффективному проникновению религии в школы, армию, космонавтику, на радио и телевидение и даже в детские сады. С. П. Королёв не мог представить даже в страшном сне, что безопасность космических полётов будет обеспечивать благословение патриарха, а присутствие высших государственных чиновников в церкви станет обязательным во время церковных праздников, как это было при царе. К этой статье примыкает статья 28 , в которой говорится о свободе совести и вероисповедания, а также «свободно выбирать, иметь и распространять религиозные и иные убеждения и действовать в соответствии с ними».

«Иные» - это, наверное, атеистические убеждения. Но такой свободной духовной атмосферы как раз и нет в современной России. Ныне русскость во многом определяется позитивным отношением к православию. Не верующий в Бога становится подозрительным, чуждым для общества человеком. Вот почему и стоят высшие чиновники в церкви во время праздников, чтобы хотя бы этим походить на верующих. В статье 52 Конституции СССР этот вопрос решался более определённо: кроме гарантированной свободы совести в ней упоминалось, в частности, право «вести атеистическую пропаганду», а также было чётко прописано: «Церковь в СССР отделена от государства и школа - от церкви».

Статья 19 говорит о равенстве людей перед законом и судом. Жизнь показывает отсутствие этого равенства. Чем выше человек в иерархии ценностей, тем менее подвластен он закону и суду. Примеры из жизни показывают, что таким «высокопоставленным» лицам дают, в основном, условные срока, или совсем освобождают от наказания, как это произошло, например, с бывшим военным министром Сердюковым. 
В статье 26 прописано право человека самому определять и указывать свою национальную принадлежность. Что этим хотели сказать разработчики конституции остаётся тайной. Ранее национальность ребёнка определялось по национальности одного из родителей, с их согласия. При этом сохранялась преемственность национальной родовой линии. Самостоятельное определение своей национальности даёт возможность каких-то спекуляций на этом вопросе. Отношение к еврею не изменится, назовись он хоть чукчей, если он будет, владея банком, заводом, торговым центром или,состоя в должности министра, обирать, унижать и эксплуатировать людей.

Статья 27 утверждает право свободного передвижения и выбора места пребывания и жительства. Однако высокие цены на транспорт установили непреодолимую преграду для свободного перемещения людей. Из-за этого, в некоторых случаях, даже произошло разъединение семей. Свобода места жительства вообще невыполнима для большинства трудящихся страны.

Свобода мысли и слова гарантированы 29 статьёй Конституции. В ней определено право свободно «производить и распространять информацию любым законным способом». Опять этим правом могут воспользоваться только люди с толстыми кошельками. Стоит привести слова В.И. Ленина по этому поводу: «Свобода в буржуазном обществе есть, в первую очередь, свобода буржуазии, для буржуазии и с целью обогащения буржуазии». Ни у кого не вызывает сомнение, что общество, построенное при содействии этой Конституции есть буржуазное, капиталистическое, как ни прикрывай его лживым названием «Конституционного строя». Свобода СМИ есть свобода рекламы, секса, насилия и пропаганды безнравственного поведения. Телевизор превратился в ящик для зомбирования населения сказочками об успехах экономики, инвестиции и модернизации, а когда в нём видишь заставку «Газпром достояние народа» застываешь в недоумении - начать смеяться или же всё-таки плакать.

Право на объединение и свобода их деятельности, указанная в статье 30 далека от жизненной действительности. Организация на производстве профсоюза, не состоящего в официальном, «независимом» профсоюзе Шмакова, скорее всего, вызовет гонения, уменьшения премии и даже может кончиться увольнением с работы. В этом реально негативном факте одна из причин слабости рабочего движения.

В статье 36 преподносится право частной собственности на землю. Здравый смысл подсказывает, что земля, как творение природы, не может быть чьей-то собственностью. В частной собственности может быть только то, что произведено своим трудом, или трудом другого лица и куплено у него. Земля не обладает свойствами товара. Она должна принадлежать всему народу. Так, по крайней мере, происходит в тех странах, где реально, а не на словах создано социальное государство, где прибыль от ведения сельского хозяйства, добычи полезных ископаемых в определённой мере делится на всех членов общества, как например, в Норвегии, Саудовской Аравии. В Советском Союзе земля принадлежала государству, а значит и всему народу, обеспечивая, как продовольственную, так и промышленную безопасность страны.

Своеобразно построение 37 статьи - «Труд свободен. Принудительный труд запрещён». Понятно, что свобода труда негарантирует сам труд - главное, чем человек зарабатывает себе на жизнь. В советском Основном Законе определялось, что: «Основу личной собственности граждан СССР составляют трудовые доходы» (статья 13), а далее в статье 40 это положение гарантировалось: «Граждане СССР имеют право на труд - т. е. на получение гарантированной работы с оплатой труда в соответствии с его количеством и качеством...». Безработица в Советском Союзе была невозможна.

В современной буржуазной России право на труд отсутствует, тем самым официально разрешается безработица, а отсюда вытекает воровство, грабежи, 
бандитизм и даже терроризм - то, что связано с падением нравственности. Тезис о запрещение принудительного труда фактически не выполняется, что видно, хотя бы по использованию труда гастарбайтеров. Не будем говорить о настоящих рабах, которые до сих пор обнаруживаются в южных районах нашей страны. Посмотрим на пенсионеров. Иной пенсионер еле ходит, здоровья нет, а он утром принуждён тянуться на работу. Его заставляет нужда - на одну государственную пенсию не проживёшь, её не хватает на питание и на оплату жилья, так что по факту принудительный труд существует.

О том, что «Материнство и детство, семья находится под защитой государства», говорит статья 38. Что же понимается под «защитой государства»? Здесь возможно произвольное толкование, которое в конституции просто не допустимо. В некоторых западных социальных странах, например, за счёт государства проводятся бесплатно дорогостоящие прививки девочкам от рака шейки матки, сохраняя жизни многим женщинам в будущем. В РФ, несмотря на обилие нефтедолларов, и наличия статьи 41 Конституции о «праве на охрану здоровья и медицинскую помощь», государство делать этого не собирается, а прививки за свой счёт по карману только богатым людям. Вот такая у нас защита детства государством.

Более понятен второй тезис: «Забота о детях, их воспитание - равное право и обязанность родителей», в котором государство отстраняется от заботы о детях, перекладывая все тяготы воспитания на плечи родителей. Но об этом не нужно было писать, во все времена, эпохи и формации детьми занимались родители. Статья вызывает впечатление пустой и бесполезной. Есть повод вспомнить о «материнском капитале», который государство обещает выдать в связи с рождением второго ребёнка в каком-то отдалённом будущем. Нет, чтобы дать эту сумму родителям при рождении ребёнка, чтобы можно было потратить её на детское питание, одежду, коляску - то о чём семья озабочена в первые месяцы его жизни. Такой лицемерный смысл буржуазного государства - обещать, но вовремя не дать.

В статье 39 сказано: «Государственные пенсии и социальные пособия устанавливаются законом». Однако существует два закона, определяющие величину и порядок предоставления пенсий: «Закон о трудовых пенсиях» и «Закон о государственном пенсионном обеспечении». Первый закон определяет пенсии трудящихся, второй - пенсии военнослужащих и федеральных государственных гражданских служащих - чиновников, значительно отличающихся по своему материальному наполнению от первогов больщую сторону.

В связи с этим привлекает внимание нарушение статьи 21: «Достоинство личности охраняется государством. Ничто не может быть основанием для его умаления». Реально достоинство трудового человека оценено ниже госслужащего. Понятно за что можно высоко оценить труд военного - он жертвовал жизнью во имя Отечества. А что героического совершил госчиновник в своей жизни? За что ему такая высокая пенсия? За угодливость в отношениях с начальством? Не секрет, что трудовые пенсии в РФ являются самыми маленькими среди многих стран мира. Часто их не хватает на самую скромную жизнь - оплату ЖКХ, государственных тарифов, а надо ещё как-то питаться! Как же хорошо было написано в 43 статье Конституции СССР: «Граждане СССР имеют право на материальное обеспечение в старости...».

Конституция РФ в статье 40 утверждает, что: «Каждый имеет право на жилище. Никто не может быть произвольно лишён жилища». Откуда же в стране такое количество бездомных, бомжей, обитающих в самых неподходящих местах: коллекторов теплотрасс, на свалках, чердаках и подвалах домов. Кто лишил их жилья? Почему они не могут воспользоваться конституционным правом на жильё? И что означает понятие «произвольно»? При советской власти человек, честно работавший на производстве, имел перспективу и реально получал бесплатное жильё. В настоящее 
время никто не обязан заботиться о твоём местообитании. Жильё ныне можно только купить по запредельным ценам, что и отражается на высоком числе бездомных.

Право на образование записано в 43 статье Конституции РФ. Обращает внимание, что бесплатное высшее образование получается «на конкурсной основе» наряду с платным обучением. Опасение вызывает динамика этой «конкуренции», растёт или уменьшается число т. н. бюджетных, бесплатных мест. В статье 45 Конституции СССР утверждалось право на обеспечение бесплатности всех видов образования, осуществления всеобщего обязательного среднего образования. В указанной статье Конституции РФ говорится, что: «Основное общее образование обязательно». Что понимается под «основным общим образованием»? Министерство образования РФ несколько лет назад отменило курс астрономии в школе. Считается ли после этого образование основным и общим? А введение изучения религии в школе под маркой ознакомления с историей культур это тоже основное и общее? И при этом власти делают вид, что сохраняется светскость государства.

Советский Союз был одним их самых образованных государств в мире. Ныне РФ откатилась по этому показателю на 50-60 места, и уровень образованности населения продолжает снижаться. Уже можно услышать от школьников, что солнце вращается вокруг Земли, а смена времён года обусловлена господом Богом. Введение ЕГЭ способствовало замене понимания предмета его зубрёжкой. По стране идёт процесс закрытия малокомплектных школ, в основном сельских. Множество беспризорных детей остаются необразованными и примитивными личностями. Буржуазное реформирование образования грозит его полным разгромом. Капиталистам не нужен образованный и думающий народ, для добычи нефти и газа ума не надо.

В 7 главе Конституции РФ приведены статьи, регламентирующие работу отечественного судопроизводства. Статья 120 говорит: «Судьи независимы и подчинены только конституции РФ и федеральному закону». Однако множество примеров говорит об обратном, взять хотя бы случай с судьёй Данилкиным, который якобы писал приговор по делу Ходорковского под диктовку. В статье 121 указано на несменяемость судей, что в нашей коррупционной реальности не совсем полезное свойство. В этой же статье записано, что: «Судопроизводство осуществляется на основе состязательности и равноправия сторон», что также отнюдь не всегда выполняется.

В совокупности со статьёй 19 о равенстве людей перед законом и судом эти положения, будь они строго выполняемы, способны были создать действительно справедливую судебную систему, решения которой доверяли бы все стороны судебного процесса. Однако жизнь показывает, что реально эти нормы Конституции не соблюдаются, вызывая у граждан паническую боязнь судопроизводства. Чтобы как-то повысить низкий градус доверия к российскому суду в 2011 году в прессе появилось «Открытое обращение представителей общественности против информационного подрыва доверии к судебной системе РФ», подписанное 55 малоизвестными общественными деятелями. Анализ письма, произведённый А. Минкиным, показал его лицемерие, не повышающее доверие общества к отечественному правосудию [3, с. 4 ].

Деятельностью правительства РФ руководит Председатель, который по статье 113 «...определяет основные направления деятельности Правительства РФ». Из статьи следует ответственность Председателя за работу всех министерств и ведомств. Однако на практике за каждый неудачный или необоснованный законопроект отвечает только руководитель министерства, где был подготовлен этот проект, а Председатель остаётся как бы в стороне. Все общественные обвинения относятся только к конкретному чиновнику, и почему-то никто не вспоминает, что Председатель Правительства несёт с ним такую же, если не большую ответственность за провал и неприятие обществом неудачного, а порой и вредного для человека законопроекта. 
За всеми правовыми нормами в РФ в соответствии со статьёй 125 должен наблюдать Конституционный суд РФ, который «...разрешает дела о соответствии Конституции РФ федеральных законов, нормативных актов Президента РФ...», а также «...даёт толкование Конституции РФ». Его деятельность, по-видимому, должна исходить из статьи 55 «В РФ не должны издаваться законы, отменяющие или умаляющие права или свободы человека и гражданина», а также соответствовать статье 15: «Конституция РФ имеет высшую юридическую силу...Законы и иные правовые акты...не должны противоречить Конституции РФ. Органы государственной власти...обязаны соблюдать Конституцию РФ и законы».

Однако проведённый анализ лишь небольшой части статей Конституции показывает их расхождение с живой юридической практикой государственных органов. Конституционному суду открыто большое поле деятельности, однако о его работе мало что известно, как будто она носит сугубо секретный характер. Появлению некоторых законодательных актов, казалось бы, не совместимых с социальным и светским характером государства, конституционный суд, обычно, не препятствует.

Наконец в части 2 статьи 80 определяется, что «Президент РФ является главой государства», и далее говорится, что он «является гарантом Конституции РФ, прав и свобод человека и гражданина», и, конечно, «Президент...определяет основные направления внутренней и внешней политики государства». Как однажды самонадеянно сказал Д. Медведев, бывший в своё время президентом на чью-то попытку его поправить: «Меня не надо поправлять. Мои слова отлиты из гранита». Главе государства, гаранту Конституции и юристу по образованию должны быть известны все несоответствия Конституции РФ реальной жизни, но, почему-то ни в одном из последних своих выступлений не было, хотя бы намёка на это несоответствие. Буржуазной власти выгодно сохранение демократически показной Конституции, соблюдаемой на деле только для богатых людей, которые деньгами могут обеспечить свою жизнь в соответствии с её статьями.

В Конституции имеются также три статьи - 57, 58, 59 - касающиеся обязанностей граждан РФ: платить налоги, сохранять природу и защищать Отечество. Статья 57 даже допускает ухудшение положения налогоплательщиков, что обычно и происходит в начале каждого года после повышения государством тарифов на ЖКХ, газ, воду, электроэнергию, которое не находит обстоятельного объяснения. А вот ввести прогрессивное налогообложение на богатых, чтобы они поделились доходами с беднейшими слоями населения, как это принято во многих капиталистических странах для развития «социального государства», которое декларировано 7 статьёй Конституции РФ, буржуазные власти, в лице президента В. Путина, категорически не желают.

Анализ Конституции РФ показывает, что она состоит из отдельных, функционально различных частей. Статьи одной части посвящены описанию общественного строя, смысл которого лицемерно скрывается в понятии конституционного строя. В этой части статей описываются основbl капиталистического общественного строя. Другая часть статей, опубликованных в 36 главах Конституции, посвящень структуреорганов власти, распределение обязанностей и подчинённость, закрепляющая на деле президентскую форму правления, в том крайне властном положении, которая, по словам историков, превышают полномочия русских царей. Третья часть статей представляет различные права и свободы людей, возможных в буржуазном государстве, но используемые, в основном, богатыми лицами. Малоимущие граждане имеют небольшую возможность пользования этими свободами и правами. Для них эти статьи носят необязательный, показной, рекламный характер. Конституция реально предназначена только для богатой части населения страны. Равенство прав и свобод человека, гарантированное 
Конституцией (статья 19, пункт 2) на деле не выполняется, порождая разделение людей по материальным и властным признакам, создавая основу для порождения сословности в России.

Разница между юридической и фактической конституциями вынуждают вспомнить давнишнюю оценку В.И. Ленина о «Фиктивности конституции, в которой законы и действительность расходятся» [2, с. 345].Фиктивность, необязательность нашей Конституции допускает безразличие и равнодушие государства к судьбам не только отдельных людей, но и всего трудящегося населения. Фиктивность Конституции РФ всё более возрастает, расхождение между фактической правовой системой и нормами Конституции РФ становится всё заметнее. Буржуазия и власти страны на основе Конституции решают, в основном, свои материальные проблемы; они не способны решать проблемы возрождения великой державы. С момента принятия российской Конституции прошло солидное время и можно судить о том, к чему привело её утверждение. За краткий по историческим меркам период произошло катастрофическое разрушение великой державы. Мы являемся свидетелями дезиндустриализации промышленности, снижения научных достижений, отката в изучении Космоса.

Несмотря на эти тревожные явления, многочисленные учебники по конституционному праву, в количестве более десятка просмотренных автором, на своих страницах ведут серьёзный, наукообразный разговор о величии Конституции РФ и её преимуществах над советскими Конституциями. Однако это надуманное, лицемерное утверждение, выполняемое в угоду буржуазной власти. В советской Конституции 1977 г. была чётко прописана благородная цель социалистического государства - повышение благосостояния людей. В Конституции России 1993 года реализуется совершенно иная цель - свобода буржуазии для извлечения прибыли путём эксплуатации народа. Совершенно различными оказались не только Конституции. Жизнь народа, несмотря на все трудности советского периода, была полноценной и насыщенной положительными эмоциями; человек был уверен в завтрашнем дне. Современная буржуазная действительность тяжким бременем давит на плечи трудящихся и пенсионеров.

Изучение обеих Конституций позволяет заметить чрезвычайную скупость последней на слова, которая по сравнению с добротной, полноценной Конституцией СССР выглядит несерьёзным ученическим произведением, хотя и выполненная с особым лицемерным мастерством. Заключительная работа над советским Основным Законом проходила в рамках всенародного, коллективного обсуждения, длившегося почти четыре месяца. За это время было подано около четырёхсот тысяч предложений о поправках. Конституционная комиссия приняла поправки к 110 статьям и разработала одну новую статью.

Совершенно иной характер наблюдался при разработке буржуазной Конституции. Работа над ней проходила в спешке, за закрытыми дверями, под прикрытием Указа Ельцина №1400. Этот Указ реализовал «источник права в материальном смысле», силовым путём изменив Конституцию СССР. Торопливость привела к тому, что было забыто дополнительное название Конституции Основным Законом, обычно приводящееся совместно, на одной титульной странице. Спешка наблюдается и в стилистическом оформлении отдельных статей, которые получили неоднозначное или не чётко выраженное содержание. Стране была навязана,открыто не обозначенная,президентская форма правления. За принятие конституции проголосовало $32 \%$ зарегистрированных избирателей, т. е. конституционное меньшинство, что не позволяет считать её утверждение легитимным.

В правоведении современного периода, как и в других социальных науках, сложилась особая ситуация, когда официальные властные документы не соответствуют 
реальным желаниям трудового народа. Противоречие властных установок народным чаяниям создаёт неустойчивое общественное состояние. Может быть, поэтому состоятельные люди, олигархи держат свои сбережения в заграничных банках. Но это уже другой вопрос, вопросо социальной устойчивости буржуазного общества России.

1. Баглай М.В. Конституционное право РФ. Учебник для юридических вузов. Москва, 2000, с. 18.

2. Ленин В.И. Как социалисты - революционеры подводят итоги революции //ПСС, т. 17, с. 345.

3. Минкин А. Подрывники, 55 кинжалов в спину российского суда. //«Московский комсомолец. РРЕ», 5-16 марта 2011, №11, с. 4.

4. Чумаков В. А. К вопросу становления философии регулятивно-диалектического материализма //Научный диалог: вопросы философии, социологии, истории, политологии. Сборник научных трудов по материалам международной научной конференции 1 октября 2016г. LJournal.ru. Самара 2016, часть 1. Издание ЦНК МНИФ «Общественные науки», с. 5-11.

\title{
Prawirayuda G.A.
}

\section{Concept of International Commercial Arbitration Practice in the Russian Federation}

\author{
Peter the Great St.Petersburg Polytechnic University
} (Russia, St.Petersburg)

doi:10.18411/spc-20-01-2018-10

idsp: 000001:spc-20-01-2018-10

Arbitration is the most formal alternative to litigation. In this process, the disputing parties present their case to a neutral third party, who renders a decision. Arbitration is widely used to resolve disputes in both the private and public sector.Governing Laws The Russian Constitution regards international treaties to which Russia is a party as an essential and supreme component of Russian law. Thus, international treaty and convention rules prevail in the event of a conflict with domestic Russian law. With respect to international arbitration, Russia is a party to the Convention on the Recognition and Enforcement of Foreign Arbitral Awards of 1958 (New York Convention) and the European Convention on International Commercial Arbitration of 1961. Russia is also a party to several bilateral treaties on the mutual recognition and enforcement of arbitral awards, including, for example, with Sweden and Japan.

Regional treaties with other Commonwealth of Independent States ("CIS") countries are an important source of law in intra-CIS disputes.The primary source of Russian international arbitration law is the law "On International Commercial Arbitration" (International Arbitration Law) enacted on July 7, 1993.The International Arbitration Law is based on the UNCITRAL Model Law; however, Russia has not adopted the amendments to the UNCITRAL Model Law that were introduced in 2006. In addition to the International Arbitration Law, ancillary rules governing interface between the courts and arbitral tribunals are set out in the Arbitrazh Procedure Code (APC).The arbitrazh courts are federal commercial courts which, in 2002, assumed responsibility from the courts of general jurisdiction for the enforcement of foreign arbitral awards and judicial support of arbitration proceedings generally.

Arbitration has several concepts that are also an arbitrage advantage compared to ordinary courts. These advantages are directly related to the principles of international commercial arbitration, the main of which are as follows:

\section{The Principle of Rapidity.}

As a rule, the time for consideration of cases in the state arbitration court is longer (the total time for consideration of cases in the courts of the first, appeal, cassation and supervisory instances is at least one year) compared with the proceedings in international commercial arbitration. The Rules of the International Commercial Arbitration Court at the Chamber of Commerce and Industry of the Russian Federation contain an indication of the 